\title{
Focal adhesion kinase as potential target for cancer therapy (Review)
}

\author{
HUIFANG HAO ${ }^{1}$, YOSHIO NAOMOTO ${ }^{1}$, XIAOHONG BAO ${ }^{1}$, NOBUYUKI WATANABE ${ }^{1}$, \\ KAZUFUMI SAKURAMA ${ }^{1}$, KAZUHIRO NOMA ${ }^{1}$, TAKAYUKI MOTOKI ${ }^{1}$, YASUKO TOMONO ${ }^{2}$, \\ TAKUYA FUKAZAWA ${ }^{1}$, YASUHIRO SHIRAKAWA ${ }^{1}$, TOMOKI YAMATSUJI ${ }^{1}$, \\ JUNJI MATSUOKA ${ }^{1}$, Z.G. WANG ${ }^{3}$ and MUNENORI TAKAOKA ${ }^{1}$
}

\author{
${ }^{1}$ Department of Gastroenterological Surgery, Transplant and Surgical Oncology, Graduate School of Medicine, Dentistry \\ and Pharmaceutical Sciences, Okayama University, Okayama; ${ }^{2}$ Shigei Medical Research Institute, Okayama, Japan; \\ ${ }^{3}$ College of Life Science, Inner Mongolia University, The Key Laboratory of Mammal Reproductive \\ Biology and Biotechnology, Ministry of Education, Huhhot, P.R. China
}

Received April 21, 2009; Accepted June 25, 2009

DOI: 10.3892/or_00000524

\begin{abstract}
Focal adhesion kinase (FAK) is a $125-\mathrm{kDa}$ non-receptor and non-membrane protein tyrosine. FAK can function with integrins and growth factor receptors to promote cell survival dependent kinase activity and nuclear FAK promotes cell proliferation and survival through FERM (FAK, ezrin, radixin, moesin) domain-enhanced p53 degradation independent kinase activity. Many previous studies have indicated that FAK plays a critical role in the biological processes of normal and cancer cells and FAK has been proposed as a potential target in cancer therapy. Small molecule inhibitors (PF-573,228; PF-562,271 and NVP-226) for use as potential cancer therapies have been developed. However, the detailed mechanism of the role for FAK in tumor cell generation and progression remain unclear, so future work is needed to explore these issues. New inhibitors that can be effectively inhibit the function of FAK still need to be explored due to the low specificity, and resistance.
\end{abstract}

\section{Contents}

1. Introduction

2. FAK structure

Correspondence to: Dr Yoshio Naomoto, Department of Gastroenterological Surgery, Transplant and Surgical Oncology, Graduate School of Medicine, Dentistry and Pharmaceutical Sciences, Okayama University, 2-5-1 Shikata-cho, Okayama 700-8558, Japan

E-mail: ynaomoto@md.okayama-u.ac.jp

Abbreviations: FAK, focal adhesion kinase; FERM, FAK-ezrinradixin-moesin homology; FRNK, FAK-related non-kinase; FAT, focal adhesion targeting; PTK, protein tyrosine kinase; FAs, focal adhesions; GTPase, guanosine triphosphatase

Key words: focal adhesion kinase, FAK-related non-kinase, FERM, FAK inhibitor
3. FAK signaling and function

4. FAK and cancer

5. FAK inhibitors

6. Conclusions

\section{Introduction}

Focal adhesion kinase (FAK) is a $125-\mathrm{kDa}$ non-receptor protein tyrosine which was originally identified in chicken embryo cells transformed by $\mathrm{v}-\mathrm{Src}$ (1) and BALB/c3T3 fibroblasts (2) and was shown to localize to focal adhesions at the same time. The FAK gene is located on human chromosome 8 q24 and mouse chromosome 15 (3). Many previous studies have indicated that FAK plays a critical role in the biological processes of normal and cancer cells and FAK has been proposed as a potential target in cancer therapy.

\section{FAK structure}

FAK is a non-receptor and non-membrane associated protein tyrosine kinase (PTK), which does not contain Src homology 2 (SH2) or $\mathrm{SH} 3$ protein interaction domains (4). FAK related PTK have been isolated and are known as cell adhesion kinase $B(\mathrm{CAK} \beta)$, protein tyrosine kinase 2, (PYK2), related adhesion focal tyrosine kinase (RAFTK), calciumdependent tyrosine kinase (CADTK), and focal adhesion kinase 2 (FAK2) (5-8). FAK contains three main domains: the centrally located catalytic kinase domain flanked by a large N-terminal domain comprising the FERM region and a C-terminal domain harboring the focal adhesion targeting (FAT) $(4,9,10)$. At least 6 tyrosine sites (Tyr-397, -407, -576, $-577,-861$ and -925$)$ need to be phosphorylated during the activation of FAK $(11,12)$. Tyr-576 and Tyr-577 are within the kinase activation loop; Tyr-861 and Tyr-925 are within the C-terminal domain (4). Growth factors or clustering of integrins facilitates the rapid phosphorylation of FAK at Tyr-397 and this in turn would recruit Src-family PTKs, resulting in the phosphorylation of Tyr-576 and Tyr-577 in 
the FAK activation loop and full catalytic FAK activation $(4,10)$.

$C$-terminal domain of FAK. The C-terminal non-catalytic domain of FAK is rich in protein-protein interaction sites, comprising two regions, one region containing two prolinerich sequences proximal to the catalytic domain; the other region is the focal adhesion targeting (FAT) sequence $(4,13)$. The FAT sequence directs FAK to newly formed and existing adhesion complexes (13). Fusion of this $15.5-\mathrm{kDa}$ fragment to other proteins is sufficient for the localization at focal adhesions (14). X-ray crystallography and nuclear magnetic resonance (NMR) analysis showed that the FAT domain is comprised of four helical bundles that resemble structures present in other adhesion proteins, including vinculin, Crk-associated substrate (Cas) and $\alpha$-catenin (15-17). The FAT is also the binding site for the adhesion associated proteins paxillin and talin $(4,10)$. Paxillin is an adaptor protein containing different interaction domains such as a prolinerich site for SH3 domain binding, four zinc-finger LIM domains which are important for paxillin targeting to focal contacts (18). The adapter protein paxillin interacts with its LD2 domain to helix 1 and with its LD4 domain to helix 3 of the FAT domain (19). Talin is a structural protein that can associate with $B$-integrin cytoplasmic tails. Binding analyses showed that the talin binding region localized at residues 965-1012 of the FAK FAT domain (20).

The entire C-terminal, non-catalytic domain of FAK (FAK related non-kinase-FRNK) is autonomously expressed in some cell types, and has been utilized as a dominant negative mutant to elucidate FAK function (21-24). Vascular smooth muscle cells have an elevated expression of FRNK and it appears that vascular injury also causes upregulation (25). In most cells, forced overexpression of FRNK inhibits cell spreading, cell migration and growth-factor mediated signals to MAP kinase (25-27).

$N$-terminal domain of FAK. The N-terminal domain of FAK contains an autophosphorylation site, Tyr-397, and a region of approximately 300 amino acids that has shown sequence homology with the band 4.1 protein/ERM proteins within a region known as the FERM domain $(4,28,29)$. FERM domains have been indicated to mediate both protein-protein interactions and protein-membrane interactions (30). The cytoplasmic tail of $\beta$-integrins and growth factor receptors, which can promote cell motility and signaling, is the best-known interaction partner of the FAK FERM domain $(31,32)$. The FAK FERM structure reveals a three-lobed (F1-F3) architecture characteristic (33). Some studies showed that truncation of the FERM domain of FAK resulted in an increase in phosphorylation of FAK and its kinase activity $(34,35)$, suggesting a negative regulatory role in FAK activation. The FERM domain of FAK can interact with the kinase domain of FAK in vitro and in vivo, proposing a direct autoinhibitory working model of FAK regulation (30). The crystal structure of FAK residues 31-686 containing the FERM and kinase domains is in accord with this model (36). The autoinhibition is a result of an interaction between the FERM domain and the kinase C-lobe and the disruption of this interaction activates the FAK kinase. The FERM domain directly binds the kinase domain, blocking access to the catalytic cleft and protecting the FAK activation loop from Src phosphorylation (36).

Some studies indicated that the FERM domain of FAK interacts with p53, regulating the signaling of the tumor cell's survival (37-39). FAK FERM functioned as a scaffold with the binding of p53 and murine double minute-2 (Mdm2) to different lobes of the FERM domain. p53 inactivation by FAK required FAK FERM F1 lobe binding to p53, FERM F2 lobe-mediated nuclear translocation, and FERM F3 lobe for connections to Mdm2 and proteasomal degradation (39). Importantly, it was found that the FERM-mediated survival pathway is a FAK kinase-independent event and needs FAK nuclear localization (39). Within FAK FERM, the nuclear localization motif is localized to the F2 lobe and is made up of a basic residue cluster (K190, K191, K216, K218, R221 and K222) contiguous at the distal tip of the F2 lobe but separated by a primary sequence (39).

\section{FAK signaling and function}

FAK has been shown to be an important mediator of cell growth, cell proliferation, cell survival and cell migration, all of which are often dysfunctional in tumor cells (40).

Integrin related signaling. The crucial step of cell cycle is integrin-mediated cell attachment to the extracellular matrix (41) and FAK is the canonical mediator of integrin signals (10). FAs are large integrin-based multiprotein complexes that mediate strong cell-substrate adhesion and transmit information in a bidirectional manner between extracellular molecules and cytoplasm (42). FAs comprise integrins, integrin-associated adaptor and signaling proteins such as FAK, Src, Grb2, p130Cas paxillin, vinculin, tensin, growth factor receptors and their related downstream targets $(42,43)$. FAK is primarily recruited to FAs by interactions between its C-terminal domain and integrin-associated proteins paxillin (44) and talin (20), resulting in autophosphorylation at Tyr-397 of FAK and total FAK activation $(11,45,46)$.

Integrin-stimulated FAK phosphorylation at Tyr-397 makes a high-affinity binding for Src-homology 2 (SH2) domain of Src-family PTKs (SFKs), leading to the conformational activation of SFKs and the formation of a transient FAK-Src signaling complex in fibroblasts and epithelial cells $(46,47)$. In turn, the binding and subsequent activation of the Src kinase results in the phosphorylation of FAK at its 'downstream' residues, Tyr-576 and Tyr-577, and maximal kinase activation (11). The adaptor proteins paxillin and p130Cas are the two main phosphorylation targets of the FAK-Src complex (46). Phosphorylation of both paxillin (residues Y31 and Y118) and p130Cas (within the Cas substrate domain) create binding sites for the $\mathrm{SH} 2$ domain of the Crk adaptor protein (48), activating small GTPase, such as Rac1 or Cdc42 and c-Jun N-terminal kinase (JNK), and the subsequent promotion of membrane protrusion and cell migration (49-51).

Integrin-stimulated FAK auto-phosphorylation at Tyr-397, Src-family PTK binding to FAK Tyr-Y397, and the formation of a FAK-Src signaling complex promote cell motility and cell survival $(46,52)$. There are several survival signaling mediated by FAK. The first is related with PI3K-Akt and FAK could 
function upstream of such survival pathways $(32,53)$. Extracellular signal via the FAK activation leads to the sequential activation of PI3K and Akt (53). Activated Akt phosphorylates BAD (member of the Bcl-2 family) Ser-136 and finally promote survival $(32,54)$. The second is extracellular signalFAK-JNK survival pathways, requiring Cas and Ras. ECM activated the formation of FAK-p130Cas complex and this complex activates C-JunNH2-terminal kinase (JNK) through a Ras/Rac1/Pac1/MAPK kinase 4. Activated JNK finally promote the survival of fibroblasts cultured on fibronectin (55). There is still a third FAK-mediated survival due to the interaction of the N-terminal of FAK with p53 and will be discussed below in detail.

FAK FERM and p53 survival signaling. It is estimated that at least $50 \%$ of human cancers is due to the ablation or dysfunction of the p53 gene (56). As a transcription factor, p53 has been implicated in the regulation of numerous tumor suppressor genes. In normal conditions, p53 expression is maintained at low levels by poly-ubiquitination and proteasomal degradation (57) and Murine double minute-2 (Mdm2) is one of several ubiquitin E3 that regulate p53 levels in cells (58). FAK and tumor suppressor gene p53 were reported to functionally connect with each other. The researchers showed that p53 controls survival signals from the extracellular matrix transduced by FAK in anchorage-dependent cells (59). In squamous cell carcinoma cells, a link between p53-mediated anoikis and FAK was demonstrated (60). A correlation between FAK and p53 overexpression was indicated via immunohistochemical analysis of 115 endometrial carcinoma samples (61). As previous described by Golubonskaya et al the N-terminal fragment of FAK directly interacts with the $\mathrm{N}$-terminal transactivation domain of $\mathrm{p} 53$, suppressing p53-mediated apoptosis and inhibiting the transcriptional activity of p53 (37).

Recently the structure of the FAK FERM was elucidated (36) and Lim et al proposed a novel FAK FERM-mediated survival pathway which is different from canonical FAK functions in two ways: it is a FAK kinase independent event and the direct regulation of $\mathrm{p} 53$ requires FAK nuclear localization (39). The authors demonstrated that FAK inhibits p53 via FAK FERM nuclear translocation, FERMmediated binding to p53, and FERM-enhanced Mdm2dependent p53 ubiquitination (39). They further stated that nuclear FAK accumulation was associated with a loss of FAK at focal contacts which is in accordance with the notion that there is a cytoplasmic pool of FAK, freely shuttling in and out of the nucleus. They proposed a model whereby under conditions of cellular stress or reduced integrin signaling, the cytoplasmic pool of FAK is elevated, leading to increased FAK nuclear accumulation, which acts to enhance cell survival by facilitating p53 turnover. It is interesting to note that some transformed cell types can survive under suspension conditions and that this associated with a reduced p53 activation (62). FAK levels are elevated in many tumor cells (63), and FAK can form a complex with p53 in both normal and tumor cells (39). However, whether FAK FERM-mediated regulation of p53 might act in a kinaseindependent manner to promote tumor progression still needs to be studied further.
Proliferation. FAK also plays an important role in regulating cell cycle progression, requiring Erk activity, cyclin D1 transcription, and the cyclin-dependent kinase (cdk) inhibitor p27 kip1 (52). Cyclin D1 is a key regulator of G1 to S phase progression the cell cycle and the transition from G1 to $S$ phase is regulated by many cyclin-dependent kinase which are controlled by phosphorylation, cyclins, and cdk inhibitors (64-66). FAK signaling regulated cyclin D1 expression at the transcription level. This regulation depends on integrinmediated cell adhesion and is likely through its activation of Erk signaling pathway (66). FAK overexpression upregulates cyclin D3 and enhances cell proliferation through the PKC and PI3K-Akt pathways $(66,67)$.

Migration and invasion. FAK also plays an important role in cell adhesion and migration $(68,69)$ its autophosphorylation and complex formation with paxillin (adhesion) and Src (migration/invasion) is necessary during these processes (32). Several FAK-mediated signaling pathways have been proposed leading to migration. One is the FAK/ CAS signaling pathway: Crk-associated substrate (CAS) proteins are phosphorylated by cellular Src binding to FAK, resulting in a Crk family adaptor molecule activation of a small GTPase, for instance Rac1 or Cdc42 and c-Jun N-terminal kinase (JNK), and the subsequent promotion of membrane protrusion and cell migration (49-51,70); also a role for PI3K in the facilitation of FAK-mediated cell migration was reported and it was proposed that the binding of Src and p130Cas to FAK may not be sufficient for the migration (71); FAK controled actin assembly via interaction with Arp2/3 complex also likely contribute to cell migration (72). FAK-deficient cells spread more slowly on extracellular matrix proteins, exhibit an increased number of prominent focal adhesions and migrate poorly in response to chemotactic signals $(31,73-75)$. When esophageal adenocarcinoma cells were treated with TAE226, which is a potent ATP competitive inhibitor of FAK, cell proliferation and migration were greatly inhibited with an apparent structural change of actin fiber and a loss of cell adhesion (76).

\section{FAK and cancer}

Numerous studies have reported FAK overexpression in various tumor cells, including neuroblastoma, pancreatic, ovarian, cervical, osteosarcoma, kidney, lung, prostate, brain, melanoma, thyroid, oral, head and neck, colon cancer, and acute myeloid leukemia (40) and its expression correlates with increased tumor malignancy. FAK mRNA levels have been shown to be increased in premalignant adenomatous tissues and invasive and metastatic tumors $(77,78)$. Increased FAK mRNA expression was demonstrated in adenomatous tissues, invasive tumors, and metastatic tumors $(77,79)$. Realtime PCR analysis of matched samples of normal colon mucosa, colorectal carcinoma, and liver metastases demonstrated increased FAK mRNA and protein levels in tumor and metastatic tissues versus normal tissues (79). Increased regional expression of FAK is found at the invasive tumor edge, implicating FAK in tumor invasion (80). Additionally, FAK is expressed in the microvascular endothelial cells of human glioma tumor biopsies and U251MG glioma xenografts, which links FAK to glioma angiogenesis (81). 
Conditional inactivation of FAK is used to study the role of FAK signaling in the processes of tumorigenesis and progress. In tumor cells, attenuation of FAK expression induces detachment and apoptosis (82), suggesting that a FAK-dependent signal is required for tumor cell growth. Furthermore, an activated form of FAK leads to resistance to anoikis (83), and FAK degradation is associated with apoptosis $(84,85)$. Overexpression of wild-type FAK in SF767 or G112P glioma cells increased cell proliferation $(86,87)$, while antisense oligonucleotides targeting FAK decreased the proliferation of U251MG cells (88). The overexpression of the C-terminal FAK carboxy-terminal domain that is produced from a separate transcript in avian cells can disrupt FAK function (21), and this protein (FRNK for FAK-related non-kinase) inhibits cell spreading and the phosphorylation of FAK, the focal adhesion protein paxillin, and, to a lesser extent, tensin (89). Researchers have exogenously expressed an analogous fragment of human FAK, which is called FAK-CD (FAK carboxy-terminal domain). They have found that FAK-CD causes cell rounding, loss of adhesion, and apoptosis in tumor cells, but not in normal cells (90-92). Other groups have also reported that a dominant-negative inhibitor, FAK-CD, did not induce apoptosis in normal cells (93). Thus, FAK-CD provides a convenient means to inactivate FAK function and dissect the signaling requirements for FAK in tumor cells. When FAK expression was selectively inhibited in skin keratinocytes, a loss of FAK suppressed chemicallyinduced skin tumor formation (94). However, increased keratinocyte cell death was observed after FAK deletion in vitro and in vivo. Elevated cell apoptosis also occurs upon conditional FAK deletion in endothelial cells (95), but not necessarily in neuronal cells (96). RNAi-mediated knockdown of FAK in aggressive breast carcinoma cells did not affect proliferation or apoptosis in culture, but carcinoma cells lacking FAK did not exhibit invasive activity in vitro or spontaneous mammary-to-lung metastasis in vivo (46).

Together elevated FAK expression and activity is associated with malignancy in a variety of cancer cells, indicating that FAK play a critical role in tumor progression. Given the role of FAK in processes important in tumorigenesis and metastasis and the link to prominent oncogenes, FAK might be a promising target in the ongoing search for anti-cancer drugs.

\section{FAK inhibitors}

FAK play a critical role in the biological processes of cancer cells, so FAK has been proposed as a potential target in cancer therapy and small molecule inhibitors for use as potential cancer therapies have been developed. Compounds: PF-573,228; PF-562,271 and NVP-226 have been recently generated by two groups. These compounds are ATP analogs and effectively inhibit the kinase activity of FAK $(97,98)$.

TAE226 is a novel ATP-competitive tyrosine kinase smallmolecule inhibitor designed to target FAK, and can effectively prevent FAK phosphorylation, extracellular signalrelated kinase (ERK), S6 ribosomal protein phosphorylation and downstream signal transduction, as determined by decreased AKT. TAE226 inhibits insulin receptor (InsR) and insulin-like growth factor-I receptor (IGF-IR), albeit, 10-fold less potently (IC50=44 $\mathrm{nM}$ for InsR and IC50=140 $\mathrm{nM}$ for IGF-IR), and is a potent inhibitor of FAK (IC50=5.5 nM) (99). TAE226 displays otherwise good selectivity against a panel of 30 kinases (99). TAE226 treatment potently disrupted glioma cell proliferation, attachment, migration, and invasion (99). TAE226 was shown to induce apoptosis in breast cancer cell lines (100). Notably, the compound efficiently increased survival rates for glioma xenografts (99) or ovarian tumor cell implants in animals (101).

PF-573,228 inhibited phosphorylation of FAK and its downstream effector paxillin, finally affected cell migration and adhesion turnover (97). But PF-573,228 had little inhibitory effect on the growth and apoptosis of normal and cancer cell and this may indicate that the FAK kinase activity is not essential for cell growth-proliferation, which is mediated through FAK FERM regulation of P53 $(39,97)$.

PF-562,271 is a newly developed diaminopyrimindinetype compound that inhibits FAK and Pyk2 and exhibits high degree of selectivity in the inhibition of PTKs (102). PF-562,271 have inhibited the tumor growth of prostate, pancreatic, colon, glioblastoma, and H460 lung xenotropic tumor models (102). PF-562,271 blocked bFGF-stimulated blood vessel angiogenesis as performed in chicken chorioallantoic membrane assays and low level administration of PF-262,271 potently blocked blood vessel sprouting without detectable changes in vascular leakage (39). PF-562,271 has since moved on to clinical trials, where it has thus far shown minimal toxicity along with some tumor regression (103). FAK inhibitors show a good application prospect for cancer therapy.

However, there are still some problems in the development of drugs that obstruct FAK function. Two of the possibilities for the developments of an inhibitor of FAK are already well explained in a review by Nimwegen and Water (32). The first possibility is inhibition of the kinase domain, thereby preventing the activation of downstream signaling cascades. But since FAK kinase activity itself may not be absolutely essential for its signaling functions, some problems have emerged. Lim et al reported that FAK FERMmediated nuclear localization of FAK promotes enhanced cell survival through the inhibition of tumor suppressor p53 independent of its kinase activity (39). Another problem with the first possibility is the specificity of the kinase inhibitor, because kinase domains of a range of different proteins show a high degree of amino acid conservation in the catalytic domains (32). The second possibility is blocking the adaptor function of FAK, such as preventing the binding of proteins to one or multiple tyrosines, to the proline rich domains or by preventing localization of FAK to the focal adhesions (32). The prevention of the association of FAK to certain binding partners will lead to a blockade of specific downstream signaling pathways, but whether it is possible to achieve this specificity in vivo still unknown because other signaling cascades might compensate for the function of FAK, resulting in the activation of the intended signaling pathways (32). Another problem within the second possibility is as to which protein-interactions should be targeted. However, interfering with the localization of FAK at the focal adhesions by the expression of the splice variant of FRNK can prevent its active role in focal adhesion signaling and focal adhesion 
turnover (103). However, targeting FAK kinase domain and its adaptor function still provides a prospective approach for cancer therapy.

\section{Conclusions}

FAK is overexpressed in a variety of cancer cells, indicating that FAK plays a critical role in tumor progression and FAK has been proposed as a potential target in cancer therapy. FAK can function with integrins and growth factor receptors to promote cell survival-dependent kinase activity and nuclear FAK promotes cell proliferation and survival through FERMenhanced p53 degradation independent kinase activity. However, whether FAK signaling within the tumor or stroma is the key event in promoting tumor progression and the detailed mechanism of the role for FAK in tumor cell generation and progression remain unclear, so future work is needed to explore these issues.

\section{References}

1. Schaller MD, Borgman CA, Cobb BS,Vines RR, Reynolds AB and Parsons JT: pp $125^{\mathrm{FAK}}$, a structurally distinctive proteintyrosine kinase associated with focal adhesions. Cell Biol 89: 5192-5196, 1992

2. Hanks SK, Calalb MB, Harper MC and Patel SK: Focal adhesion protein-tyrosine kinase phosphorylated in response to cell attachment to fibronectin. Cell Biol 89: 8487-8491, 1992.

3. Fiedorek FT Jr and Kay ES: Mapping of the focal adhesion kinase (Fak) gene to mouse chromosome 15 and human chromosome 8. Mamm Genome 6: 123-126, 1995.

4. Schaller MD: Biochemical signals and biological responses elicited by the focal adhesion kinase. Biochim Biophys Acta 1540: 1-21, 2001

5. Sasaki H, Nagura K, Ishino M, Tobioka H, Kotanik K and Sasaki T: Cloning and kinase characterization of cell adhesion kinase beta, a novel protein-tyrosine kinase of the focal adhesion subfamily. J Biol Chem 270: 21206-21219, 1995.

6. Lev S, Moreno H, Martinez R, Canoll P, Peles E, Musacchio JM, Plowman GD, Rudy B and Schlessinger J: Protein tyrosine kinase PYK2 involved in $\mathrm{Ca}(2+)$-induced regulation of ion channel and MAP kinase functions. Nature 376: 737-745, 1995.

7. Avraham S, London R, Fu Y, et al: Identification and characterization of a novel related adhesion focal tyrosine kinase (RAFTK) from megakaryocytes and brain. J Biol Chem 270: 27742-27751, 1995.

8. Yu H, Li X, Marchetto GS, Dy R, Hunter D, Calvo B, Dawson TL, Wilm M, Anderegg RJ, Graves LM and Earp HS: Activation of a novel calcium-dependent protein-tyrosine kinase. Correlation with c-Jun N-terminal kinase but not mitogen-activated protein kinase activation. J Biol Chem 271: 29993-29998, 1996.

9. Zachary I: Focal adhesion kinase. Int J Biochem Cell Biol 29: 929-934, 1997.

10. Parsons JT: Focal adhesion kinase: the first ten years. J Cell Sci 116: 1409-1416, 2003.

11. Calalb MB, Polte TR and Hanks SK: Tyrosine phosphorylation of focal adhesion kinase at sites in the catalytic domain regulates kinase activity: a role for Src family kinase. Mol Cell Biol 15: 954-963, 1995.

12. Schlaepfer DD and Hunter T: Signal transduction from the extracellular matrix - a role for the focal adhesion-tyrosine kinase FAK. Cell Struct Funct 21: 445-450, 1996.

13. Martin KH, Boerner SA and Parsons JT: Regulation of focal adhesion targeting and inhibitory functions of the FAK related protein FRNKN using a novel estrogen receptor 'switch'. Cell Motil Cytoskeleton 51: 76-88, 2002.

14. Hildebrand JD, Schaller MD and Parsons JT: Identification of sequences required for the efficient loclization of the focal adhesion kinase, pp125FAK, to cellular focal adhesions. J Cell Biol 123: 993-1005, 1993.

15. Arold ST, Hoellerer MK and Noble ME: The structural basis of localization and signaling by the focal adhesion targeting domain. Structure 10: 319-327, 2002.
16. Hayashi I, Vuori K and Liddington RC: The focal adhesion targeting (FAT) region of focal adhesion kinase is a fourhelix bundle that binds paxillin. Nat Struct Biol 9: 101-106, 2002.

17. Liu G, Guibao CD and Zheng J: Structural insight into the mechanisms of targeting and signaling of focal adhesion kinase. Mol Cell Biol 22: 2751-2760, 2002.

18. Brown MC, Perrotta JA and Turner CE: Identification of LIM3 as the principal determinant of paxillin focal adhesion localization and characterization of a novel motif on paxillin directing vinculin and focal adhesion kinase binding. J Cell Biol 135: 1109-1123, 1996.

19. Bertolucci CM, Guibao CD and Zheng J: Structural features of the focal adhesion kinase-paxillin complex give insight into the dynamics of focal adhesion assembly. Protein Sci 14: 644-652, 2005.

20. Chen HC, Appeddu PA, Parsons JT, Hildebrand JD, Schaller MD and Guan JL: Interaction of focal adhesion kinase with cytoskeletal protein talin. J Biol Chem 270: 16995-16999, 1995.

21. Schaller MD, Borgman CA and Parsons JT: Autonomous expression of a non-catalytic domain of the focal adhesionassociated protein tyrosine kinase pp125FAK. Mol Cell Biol 13: 785-791, 1993.

22. Nolan K, Lacoste J and Parsons JT: Regulated expression of focal adhesion kinase-related non-kinase, the autonomously expressed c-terminal domain of focal adhesion kinase. Mol Cell 19: 6120-6129, 1999.

23. Richardson A and Parsons T: A mechanism for regulation of the adhesion-associated protein tyrosine kinase $\mathrm{pp} 125^{\mathrm{FAK}}$. Nature 380: 538-540, 1996.

24. Taylor JM, Rovin JD and Parsons JT: A Role for focal adhesion kinase in phenylephrine-induced hypertrophy of rat ventricular cardiomyocytes. J Biol Chem 275: 19250-19257, 2000.

25. Taylor JM, Mack CP, Nolan K, Regan CP, Owens GK and Parsons JT: Selective expression of an endogenous inhibitor of FAK regulates proliferation and migration of vascular smooth muscle cells. Mol Cell Biol 21: 1565-1572, 2001.

26. Hauck CR, Sieg DJ, Hsia DA, Loftus JC, Gaarde WA, Monia BP and Schlaepfer DD: Inhibition of focal adhesion kinase expression or activity disrupts epidermal growth factor-stimulated signaling promoting the migration of invasive human carcinoma cells. Cancer Res 61: 7079-7090, 2001.

27. Richardson A, Shannon JD, Adams RB, Schaller MD and Parsons: Identification of integrin-stimulated sites of serine phosphorylation in FRNK, the separately expressed C-terminal domain of focal adhesion kinase: a potential role for protein kinase A. Biochem J 324: 141-149, 1997.

28. Chishti AH, Kim AC, Marfatia SM, et al: The FERM domain: a unique module involved in the linkage of cytoplasmic proteins to the membrane. Trends Biochem Sci 23: 281-282, 1998.

29. Girault JA, Labesse G, Mornon JP and C: Theallebaut I: Ntermini of FAK and JAKs contain divergent band 4.1 domains. Trends Biochem Sci 24: 54-57, 1999.

30. Cooper LA, Shen TL and Guan JL: Regulation of focal adhesion kinase by its amino-terminal domain through an autoinhibitory interaction. Mol Cell Biol 23: 8030-8041, 2003.

31. Sieg DJ, Hauck CR, Ilic D, Klingbeil CK, Schaefer E, Damsky CH and Schlaepfer DD: FAK integrates growthfactor and integrin signals to promote cell migration. Nat Cell Biol 2: 249-256, 2000.

32. Van Nimwegen MJ and van de Water B: Focal adhesion kinase: a potential target in cancer therapy. Biochem Pharmacol 73: 597-609, 2007.

33. Ceccarelli DF, Song HK, Poy F, Schaller MD and Eck MJ: Crystal structure of the FERM domain of focal adhesion kinase. J Biol Chem 281: 252-259, 2006.

34. Chan PY, Kanner SB, Whitney G and Aruffo A: A transmembrane-anchored chimeric focal adhesion kinase is constitutively activated and phosphorylated at tyrosine residues identical to pp125FAK. J Biol Chem 269: 20567-20574, 1994.

35. Schlaepfer DD and Hunter T: Evidence for in vivo phosphorylation of the Grb2 SH2-domain binding site on focal adhesion kinase by Src-family protein-tyrosine kinases. Mol Cell Biol 16: 5623-5633, 1996.

36. Lietha D, Cai X, Ceccarelli DF, Li Y, Schaller MD and Eck MJ: Structural basis for the autoinhibition of focal adhesion kinase. Cell 129: 1177-1187, 2007. 
37. Golubovskaya VM, Finch R and Cance WG: Direct interaction of the N-terminal domain of focal adhesion kinase with the $\mathrm{N}$-terminal transactivation domain of p53. Biol Chem 280 25008-25021, 2005

38. Golubovskaya VM, Finch R, Kweh F, Massoll NA, CampbellThompson M, Wallace MR and Cance WG: p53 regulates FAK expression in human tumor cells. Mol Carcinog 47: 373-382, 2008.

39. Lim ST, Chen XL, Lim Y, Hanson DA, Vo TT, Howerton K, Larocque N, Fisher SJ, Schlaepfer DD and Ilic D: Nuclear FAK promotes cell proliferation and survival through FERMenhanced p53 degradation. Mol Cell 29: 9-22, 2008.

40. Golubovskaya VM, Kweh FA and Cance WG: Focal adhesion kinase and cancer. Histol Histopathol 24: 503-510, 2009.

41. Assoian RK and Klein EA: Growth control by intracellular tension and extracellular stiffness trends. Cell Biol 18: 347-352, 2008.

42. Cukierman E, Pankov R, Stevens DR and Yamada KM: Taking cell-matrix adhesions to the third dimension. Science 294: 1708-1712, 2001.

43. Hehlgans S, Haase M and Cordes N: Signalling via integrins: implications for cell survival and anticancer strategies. Biochim Biophys Acta 1775: 163-180, 2007.

44. Tachibana K, Sato T, D'Avirro N and Morimoto C: Direct association of pp $125 \mathrm{FAK}$ with paxillin the focal adhesiontargeting mechanism of pp125FAK. J Exp Med 182: 1089-1099, 1995

45. Kornberg L, Earp HS, Parsons JT, Schaller M and Juliano RL: Cell adhesion or integrin clustering increase phosphorylation of a focal adhesion-associated tyrosine kinase. J Biol Chem 267: 23439-23442, 1992.

46. Mitra SK and Schlaepfer DD: Integrin-regulated FAK-Src signaling in normal and cancer cells. Curr Opin Cell Biol 18: 516-523, 2006

47. Schlaepfer DD, Mitra SK and Ilic D: Control of motile and invasive cell phenotypes by focal adhesion kinase. Biochim Biophys Acta 1692: 77-102, 2004.

48. Playford MP and Schaller MD: The interplay between Src and integrins in normal and tumor biology. Oncogene 23: 7928-7946, 2004

49. Cho SY and Klemke RL: Extracellular-regulated kinase activation and Cas/Crk coupling regulate cell migration and suppress apoptosis during invasion of the extracellular matrix. J Cell Biol 149: 223-236, 2000.

50. Klemke RL, Leng J, Molander R, Brooks PC, Vuori K and Cheresh DA: CAS/Crk coupling serves as a 'molecular switch' for induction of cell migration. J Cell Biol 140: 961-972, 1998

51. Dolfi F, Garcia-Guzman M, Ojaniemi M, Nakamura H, Matsuda $\mathrm{M}$ and Vuori $\mathrm{K}$ : The adaptor protein Crk connects multiple cellular stimuli to the JNK signaling pathway. Proc Natl Acad Sci USA 95: 15394-15399, 1998.

52. Cox BD, Natarajan M, Stettner MR and Gladson CL: New concepts regarding focal adhesion kinase promotion of cell migration and proliferation. J Cell Biochem 99: 35-52, 2006.

53. Sonoda Y, Watanabe S, Matsumoto Y, Aizu-Yokota E and Kasahara T: FAK is the upstream signal protein of the phosphatidylinositol 3-Kinase-Akt survival pathway in hydrogen peroxide-induced apoptosis of a human glioblastoma cell line. J Biol Chem 274: 10566-10570, 1999.

54. Datta SR, Dudek H, Tao X, Masters S, Fu H, Gotoh Y and Greenberg ME: Akt phosphorylation of BAD couples survival signals to the cell-intrinsic death machinery. Cell 91: 231-241, 1997

55. Almeida EA, Ilic D, Han Q, Hauck CR, Jin F, Kawakatsu H, Scjlaepfer DD and Damsky $\mathrm{CH}$ : Matrix survival signaling from fibronectin via focal adhesion kinase to C-Jun Nh2-terminal kinase. J Cell Biol 149: 741-754, 2000.

56. Russo A, Bazan V, Iacopetta B, Kerr D, Soussi T, Gebbia N and TP53-CRC Collaborative Study Group: The TP53 colorecta cancer international collaborative study on the prognostic and predictive significance of p53 mutation: influence of tumor site, type of mutation, and adjuvant treatment. J Clin Oncol 23: 7518-7528, 2005.

57. Vousden KH: Switching from life to death: the Miz-ing link between Myc and p53. Cancer Cell 2: 351-352, 2002

58. Iwakuma T and Lozano G: MDM2: an introduction. Mol Cancer Res 1: 993-1000, 2003.

59. Ilic D, Almeida EA, Schlaepfer DD, Dazin P, Aizawa S and Damsky CH: Extracellular matrix survival signals transduced by focal adhesion kinase suppress p53-mediated apoptosis. J Cell Biol 143: 547-560, 1998.
60. Zhang Y, Lu H, Dazin P and Kapila Y: Squamous cell carcinoma cell aggregates escape suspension-induced, p53-mediated Anoikis: fibronectin and integrin alphav mediate survival signals through focal adhesion kinase. J Biol Chem 279: 48342-48349, 2004 .

61. Livasy CA, Moore D, Cance WG and Lininger RA: Focal adhesion kinase overexpression in endometrial neoplasia. Appl Immunohistochem Mol Morphol 12: 342-345, 2004.

62. Lewis JM, Truong TN and Schwartz MA: Integrins regulate the apoptotic response to DNA damage through modulation of p53. Proc Natl Acad Sci USA 99: 3627-3632, 2002.

63. McLean GW, Carragher NO, Avizienyte E, Evans J, Brunton VG and Frame MC: The role of focal-adhesion kinase in cancer, a new therapeutic opportunity. Nat Rev Cancer 5: 505-515, 2005.

64. Sonoda Y, Matsumoto Y, Funakoshi M, Yamamoto D, Hanks SK and Kasahara T: Anti-apoptotic role of focal adhesion kinase (FAK). Induction of inhbitor-of-apoptosis proteins and apoptosis suppression by the overexpression of FAK in a human leukemic cell line, HL-60. J Biol Chem 275: 16309-16315, 2000

65. Draetta GF: Mammalian G1 cyclins. Curr Opin Cell Biol 6: 842-846, 1994

66. ZhaoJ, Pestell R and Guan JL: Transcriptional activation of cyclin D1 promoter by FAK contributes to cell cycle progression. Mol Biol Cell 12: 4066-4077, 2001.

67. Yamamoto D, Sonoda Y, Hasegawa M, Funakoshi-Tago M, Aizu-Yokota E and Kasahara T: FAK overexpression upregulates cyclin $\mathrm{D} 3$ and enhances cell proliferation via the $\mathrm{PKC}$ and PI3-kinase-Akt pathways. Cell Signal 15: 575-583, 2003.

68. Burridge K, Turner CE and Romer LH: Tyrosine phosphorylation of paxillin and pp125FAK accompanies cell adhesion to extracellular matrix: a role in cytoskeletal assembly. J Cell Biol 119: 893-903, 1992.

69. Cary LA, Chang JF and Guan JL: Stimulation of cell migration by overexpression of focal adhesion kinase and its association with Src and Fyn. J Cell Sci 109: 1787-1794, 1996.

70. Cary LA, Han DC, Polte TR, Hanks SK and Guan JL: Identification of $\mathrm{p} 130^{\mathrm{Cas}}$ as a mediator of focal adhesion kinasepromoted cell migration. J Cell Biol 140: 211-221, 1998.

71. Reiske HR, Kao SC, Cary LA, Guan JL, Lai JF and Chen HC: Requirement of phosphatidylinositol 3-Kinase in focal adhesion kinase-promoted cell migration. J Biol Chem 274: 12361-12366, 1999.

72. Serrels B, Serrels A, Brunton VG, Holt M, Mclean GW, Gray $\mathrm{CH}$, Jones GE and Frame MC: Focal adhesion kinase controls actin assembly via a FERM-mediated interaction with the Arp2/3 complex. Nat Cell Biol 9: 1046-1056, 2007.

73. Ilic D, Furuta Y, Kanazawa S, Takeda N, Sobue K, Nakatsuji N, Nomura S, Fujimoto J, Okada M and Yamamoto T: Reduced cell motility and enhanced focal adhesion contact formation in cells from FAK-deficient mice. Nature 377: 539-544, 1995.

74. Owen JD, Ruest PJ, Fry DW and Hanks SK: Induced focal adhesion kinase (FAK) expression in FAK null cells enhances cell spreading and migration requiring Both auto- and activation loop phosphorylation sites and inhibits adhesion-dependent tyrosine phosphorylation of Pyk2. Mol Cell Biol 19: 4806-4818, 1999.

75. Sieg DJ, Hauck CR and Schlaepfer DD: Required role of focal adhesion kinase (FAK) for intergrin stimulated cell migration. J Cell Sci 112: 2677-2691, 1999.

76. Watanabe N, Takaoka M, Sakurama K, et al: Dual tyrosine kinase inhibitor for focal adhesion kinase and insulin-like growth factor-I receptor exhibits anticancer effect in esophageal adenocarcinoma in vitro and in vivo. Clin Cancer Res 14: 4631-4639, 2008

77. Weiner TM, Liu ET, Craven RJ and Cance WG: Expression of focal adhesion kinase gene and invasive cancer. Lancet 342: 1024-1025, 1993 .

78. Lightfoot HM Jr, Lark A, Livasy CA, Moore DT, Cowan D Dressler L, Craven RJ and Cance WG: Upregulation of focal adhesion kinase (FAK) expression in ductal carcinoma in situ (DCIS) is an early event in breast tumorigenesis. Breast Cancer Res Treat 88: 109-116, 2004.

79. Lark AL, Livasy CA, Calvo B, Caskey L, Moore DT, Yang X and Cance WG: Overexpression of focal adhesion kinase in primary colorectal carcinomas and colorectal liver metastases. Clin Cancer Res 9: 215-222, 2003. 
80. Zagzag D, Friedlander DR, Margolis B, Grumet M, Semenza GL, Zhong H, Simons JW, Holash J, Wiegand SJ and Yancopoulos GD: Molecular events implicated in brain tumor angiogenesis and invasion. Pediatr Neurosurg 33: 49-55, 2000.

81. Haskell H, Natarajan M, Hecker TP, Ding Q, Stewart J Jr, Grammer JR and Gladson CL: Focal adhesion kinase is expressed in the angiogenic bloodvessels of malignant astrocytic tumors in vivo and promotes capillary tubeformation of brain microvascular endothelial cells. Clin Cancer Res 9: 2157-2165, 2003

82. Xu LH, Owens LV, Sturge GC, Yang X, Liu ET, Craven RJ and Cance WG: Attenuation of the expression of the focal adhesion induces apoptosis in tumor cells. Cell Growth Differ 7: 413-418, 1996.

83. Frisch SM, Vuori K, Ruoslahti E and Chan-Hui PY: Control of adhesion-dependent cell by focal adhesion kinase. J Cell Biol 134: 793-799, 1996

84. Crouch DH, Fincham VJ and Frame MC: Targeted proteolusis of the focal adhesion kinase pp125FAK during c-MYC-induced apoptosis is suppressed by intergrin signalling. Oncogene 12 : 2689-2696, 1996.

85. Wen LP, Fahrni JA, Troie S, Guan JL, Orth K and Rosen GD: Cleavage of focal adhesion kinase by caspases during apoptosis. J Biol Chem 272: 26056-26061, 1997.

86. Lipinski CA, Tran NL, Bay C, Kloss J, McDonough WS, Beaudry C, Berens ME and Loftus JC: Differential role of prolinerich tyrosine kinase 2 and focal adhesion kinase in determining glioblastoma migration and proliferation. Mol Cancer Res 1: 323-332, 2003

87. Lipinski CA, Tran NL, Menashi E, Rohl C, Kloss J, Bay RC, Berens ME and Loftus JC: The tyrosine kinase PYK2 promotes migration and invasion of glioma cells. Neoplasia 7: 435-445, 2005.

88. Wu ZM, Yuan XH, Jiang PC, Li ZQ and Wu T: Antisense oligonucleodes targeting the focal adhesion kinase inhibit proliferation, induce apoptosis and cooperate with cytotoxic drugs in human glioma cells. J Neurooncol 77: 117-123, 2006.

89. Richardson A, Malik RK, Hildebrand JD and Parsons JT: Inhibition of cell spreading by expression of the C-terminal domain of focal adhesion kinase (FAK) is rescued by coexpression of Src or catalytically inactive FAK: a role for paxillin tyrosine phosphorylation. Mol Cell Biol 17: 6906-6914, 1997.

90. Xu LH, Yang X, Craven RJ and Cance WG: The COOHterminal domain of the focal adhesion kinase induces loss of adhesion and cell death in human tumor cells. Cell Growth Differ 9: 999-1005, 1998.
91. Xu LH, Yang X, Bradham CA, Brenner DA, Baldwin AS Jr, Craven RJ and Cance WG: The focal adhesion kinase suppresses transformation-associated, anchorage-independent apoptosis in human breast cancer cells. J Biol Chem 275: 30597-305604, 2000.

92. Golubovskaya V, Beviglia L, Xu LH, Earp HS III, Craven R and Cance W: Dual inhibition of focal adhesion kinase and epidermal growth factor receptor pathways cooperatively induces death receptor-mediated apoptosis in human breast cancer cells. J Biol Chem 277: 38978-38987, 2002.

93. Xiong W and Parsons JT: Induction of apoptosis after expression of PYK2, a tyrosine kinase structurally related to focal adhesion kinase. J Cell Biol 139: 529-539, 1997.

94. McLean GW, Komiyama NH, Serrels B, et al: Specific deletion of focal adhesion kinase suppresses tumor formation and blocks malignant progression. Genes Dev 18: 29983003, 2004

95. Shen TL, Park AY, Alcaraz A, Peng X, Jang I, Koni P, Flavell RA, Gu H and Guan JL: Conditional knockout of focal adhesion kinase in endothelial cells reveals its role in angiogenesis and vascular development in late embryogenesis. J Cell Biol 169: 941-952, 2005.

96. Beggs HE, Schahin-Reed D, Zang K, Goebbels S, Nave KA Gorski J, Jones KR, Sretavan D and Reichardt LF: FAK deficiency in cells contributing to the basal lamina results in cortical abnormalities resembling congenital muscular dystrophies. Neuron 40: 501-514, 2003.

97. Slack-Davis JK, Martin KH, Tilghman RW, et al: Cellular characterization of a novel focal adhesion kinase inhibitor. J Biol Chem 282: 14845-14852, 2007.

98. Shi Q, Hjelmeland AB, Keir ST, et al: A novel low-molecular weight inhibitor of focal adhesion kinase, TAE226, inhibits glioma growth. Mol Carcinog 46: 488-496, 2007.

99. Liu TJ, LaFortune T, Honda T, et al: Inhibition of both focal adhesion kinase and insulin-like growth factor-I receptor kinase suppresses glioma proliferation in vitro and in vivo. Mol Cancer Ther 6: 1357-1367, 2007.

100. Golubovskaya VM, Virnig C and Cance WG: TAE226-induced apoptosis in breast cancer cells with overexpressed Src or EGFR. Mol Carcinog 47: 222-234,2008.

101. Halder J, Lin YG, Merritt WM, et al: Therapeutic efficacy of a novel focal adhesion kinase inhibitor TAE226 in ovarian carcinoma. Cancer Res 67: 10976-10983, 2007.

102. Roberts WG, Ung E, Whalen P, et al: Antitumor activity and pharmacology of a selective focal adhesion kinase inhibitor, PF-562,271. Cancer Res 68: 1935-1944, 2008.

103. Gabarra-Niecko V, Schaller MD and Dunty JM: FAK regulates biological processes important for the pathogenesis of cancer. Cancer Metastasis Rev 22: 359-374, 2003. 